human sacrifice as part of a burial ceremonial. Not only is the eagle figure unique, but also human sacrifice is a new element in finds in other branches of the Hopewellian culture. The culture of the Mound Builders, which developed between the beginning of the Christian era and Columbian times, had disappeared before the arrival of Europeans. The suggested connexion between this culture and that of Mexico and Central America might well account for the appearance of human sacrifice, to which the inhabitants of Mexico were particularly addicted.

\section{Murder by Children and Adolescents}

IN his inaugural thesis (Thèse de Paris, No. 108; 1940), Dr. Louis Begon, who records seven cases of attempted murder committed by males aged fourteen to nineteen, states that the motives for murder at this age show a much greater variety and are much more complicated than in the case of adults. The medicopsychological examination of cases of murder by young persons is of considerable practical interest both as regards the outlook of the case and the prognosis. The offenders may be classified in three different groups. The first consists of those guilty of a single offence. In such cases the prognosis is good, and a relapse is not likely to occur, provided that a change is made in the environment, which has an important influence on the determination of the act. The second group consists of those in whom murder is the result of disease. In such cases internment is required. The third group is formed by abnormal persons who are not really insane or suitable for detention in an asylum, but are dangerous individuals against whom society should be protected, in the absence of which protection a recurrence will probably happen.

\section{Tuberculosis in Mental Hospitals}

IN a paper (Amer. J. Psychiat., 96, 1335; 1940) based on his experience of pulmonary tuberculosis in mental hospitals during the last nine years, Dr. C. A. Wicks states that though the tuberculosis mortality rate for patients in the Ontario mental hospitals has shown a tendency to decrease since 1934, in 1936 the rate was fourteen times greater than that for the province as a whole. Approximately $2 \cdot 5$ per cent of 2,908 patients admitted to the Ontario mental hospitals during 1938 required isolation on account of X-ray findings in the chest. From the tuberculosis situation as it existed in January 1939 it was estimated that a central tuberculosis mental hospital would be required to accommodate approximately 5.2 per cent of the patients in Ontario mental hospitals. X-ray examination of the chest in 2,542 staff in the Ontario mental hospitals in 1937-38 showed that 0.6 per cent required treatment for tuberculosis. Since 1933, about 0.5 per cent of the employees have needed such treatment every year. About 1.7 per cent of 839 apparently healthy applicants or new staff in the Ontario mental hospital service during the calendar year 1938 showed X-ray evidence of pulmonary tuberculosis which was active or possibly active, thereby rendering them unacceptable for employment.

\section{Public Health and Advertising}

IN a paper read before the Health Officers' Section of the American Public Health Association (Amer. $J$. Public Health, 30, 880; 1940) Dr. K. E. Miller, medical director, U.S. Public Health Service, remarks that unrestrained advertising becomes a matter of public health concern primarily in connexion with those products which either directly or indirectly affect public health, such as foods, drugs and cosmetics. He points out that one of the most potent means for regulating unfair practices and protecting public health interests consists in the control of false and misleading advertisements, especially of those products which may be injurious to health. Apart from changes in the existing laws, State and local health forces can make valuable contributions to the success of the campaign against dangerous nostrums and the advertising of other medicinal products.

\section{Fatal Accidents in the United States}

According to the Journal of the American Medical Association of August 10, p. 470, the United States Bureau of the Census recently published a statistical study of fatal accidents in the six years 1933-1938. In 1933, fatalities from accidents totalled 90,932 , and thereafter the number rose to a maximum of 110,052 in 1936. Then it decreased to 93,805 in 1938 . Deaths caused by fires, which ranked seventh among all accidental causes during 1933-37, advanced to the sixth place in 1938. Figures for the successive years were 1,521 in $1933,1,752$ in $1934,1,581$ in 1935, 1,913 in $1936,1,688$ in 1937 and 1,650 in 1938. There were more victims from fire in the age group 5-9 than in any other group in 1938; there were 129 deaths in this group, which was $7 \cdot 8$ per cent of all persons burnt to death. The next largest number was in the group 50-54 with 109 deaths. Only $18 \cdot 3$ per cent of deaths from injury by fall occurred among persons less than forty-five years of age, who form 77 per cent of the population, but 55.8 per cent of the motor fatalities and $91 \cdot 3$ per cent of aeroplane fatalities were in this younger group.

\section{Improvement of Grassland}

GRassland improvement is the main theme of the July number of the Scottish Journal of Agriculture (23, No. 1, H.M. Stationery Office. Is., postage extra). Viewing the subject as a whole, a moderately longterm policy for higher farming is advocated, since facilities for improvement are now specially favourable, and stock-carrying capacity must be increased and fertility built up for the future. As a means of maintaining hill grazing as an economic proposition, the introduction of cattle, or a considerable increase in their numbers, is suggested. Bracken control is also dealt with in some detail, and the various machines recently used for this purpose described. With regard to the renovation of old pasture, practical 